\title{
Effect of Natural Antioxidants on the Stability of Linseed Oil and Fish Stored under Anaerobic Conditions
}

\author{
Kinga Śpitalniak-Bajerska, ${ }^{1}$ Antoni Szumny, ${ }^{2}$ Alicja Zofia Kucharska (D), \\ and Robert Kupczyński iD ${ }^{1}$ \\ ${ }^{1}$ Department of Environment Hygiene and Animal Welfare, Faculty of Biology and Animal Science, \\ Wroclaw University of Environmental and Life Sciences, Chelmonskiego 38c, 51-630 Wroclaw, Poland \\ ${ }^{2}$ Department of Chemistry, Faculty of Biotechnology and Food Sciences, Wroclaw University of Environmental and Life Sciences, \\ Norwida 25, 50-375 Wroclaw, Poland \\ ${ }^{3}$ Department of Fruit, Vegetable and Plant Nutraceutical Technology, Faculty of Biotechnology and Food Sciences, \\ Wroclaw University of Environmental and Life Sciences, Chelmonskiego 37, 51-630 Wroclaw, Poland
}

Correspondence should be addressed to Robert Kupczyński; robert.kupczynski@upwr.edu.pl

Received 23 May 2018; Revised 30 July 2018; Accepted 15 August 2018; Published 30 September 2018

Academic Editor: Ami Patel

Copyright (C) 2018 Kinga Śpitalniak-Bajerska et al. This is an open access article distributed under the Creative Commons Attribution License, which permits unrestricted use, distribution, and reproduction in any medium, provided the original work is properly cited.

\begin{abstract}
Vegetable and animal oils are susceptible to the oxidation of their lipid components on storage. Polyphenols from apple peels are investigated as potential natural antioxidants used for stabilizing polyunsaturated fatty acid and preventing oxidation. The aim of this study was assessing the antioxidant efficacy of apple pomace as natural antioxidant in linseed and fish oils, stored in anaerobic conditions. Apple pomace was added to the linseed and fish oils stored for eight weeks to evaluate the antioxidant activity of their polyphenolic components. The total phenolic content, activity of DPPH, ABTS ${ }^{\bullet+}$, FRAP, acid value (AV), peroxide value (PV), and fatty acid profile were analyzed in storage tests. We found that apple pomace, regardless of the oil content of the formulation, was capable of blanking 2,2-diphenyl-1-picrylhydrazyl radicals. The highest ability to reduce Fe ${ }^{3+}$ ions occurred in the samples containing $30 \%$ of the fish oil. The use of apple pomace comprising polyphenolic compounds improves the stability of linseed and fish oils in storage tests. Polyphenols in apple pomace show a high antioxidant potential, as indicated by their values of DPPH, $\mathrm{ABST}^{\bullet+}$, and FRAP. The addition of apple pomace resulted in limiting the acid and peroxide values of the samples during storage.
\end{abstract}

\section{Introduction}

Lipid oxidation is an essential reason for deterioration in the quality of edible oils $[1,2]$. The lipid oxidation products formed adversely affect the quality of food articles by altering their sensory properties and reducing their nutritive value [2]. The products become toxic and may have a negative health effect when eaten, potentially leading to numerous diseases, e.g., heart conditions or cancer $[2,3]$.

Cold-pressed vegetable oils, especially those containing $n-3$ unsaturated fatty acids, are an important component of a healthy diet. Their specific chemical structure and the presence of reactive chemical bonds make them susceptible to peroxidation. Although it is a common practice in the food-processing industry to use synthetic antioxidants, such as BHA (butylhydroxyanisol), BHT (butylhydroxytoluene), TBHQ (tert-butylhydroquinone), natural antioxidants, including extracts from the seeds of oil plants, vegetable oils, extracts of plants such as rosemary, oregano olive waste cake extract, clove (Syzygium aromaticum), and cinnamon (Cinnamomum zeylanicum) are becoming more and more popular [4-6]. The synthetic antioxidants may have an adverse health effect, being toxic or cancerogenic, disturbing enzyme synthesis and activity [7]. In addition, commercial antioxidants (such as DHA) may damage DNA by binding nucleic acids and show cytotoxic or mutagenic activity [8]. 
There are earlier reports on the applicability of fruitprocessing waste for the protection of lipids in foods against changes resulting from oxidation $[9,10]$. The antioxidant properties of fruit extracts depend on both the level and the qualitative composition of phenolic compounds in the formulation. Apple pomace is a food-processing waste identified in numerous studies as a valuable source of natural antioxidants and bioactive compounds [2, 11, 12]. Usually, the waste from fruit pressing in juice production is used as a farm animal feed or as a fertilizer. It is also used for improving the stability of meat-based products or brown rice-based cracker $[13,14]$. Fruits are a valuable source of phenolic compounds [15]. On the contrary, the use of certain vegetable oils or fish oil for feeding animals facilitates changes of the fatty acid profile in meat or milk $[16,17]$. Recent years have witnessed particular interest in the use of fatty additives potentially increasing CLA or $n-3$ acids $[18,19]$. Earlier reports demonstrated a considerable usefulness of apple pomace for improving the stability of fats in samples stored in aerobic conditions [20]. Therefore, the aim of the present research was to assess the antioxidant efficacy of apple pomace as natural antioxidant in the storage of linseed and fish oils in anaerobic conditions.

\section{Materials and Methods}

2.1. Experimental Design. The study involved vegetable (linseed) oil and animal (fish) oil with different fatty acid profiles, especially with respect to their content of long-chain fatty acids. The linseed oil (BiqOIL Laboratorium) and the fish oil (PPHW Tronina, Poland) were purchased on the wholesale market. The "Cortland" variety apple pomace was a waste material from "Maciejowy Sad" juice production. The apple pomace was dried in a laboratory oven at $60^{\circ} \mathrm{C}$ (Pol-Eko Aparatura, type SLW $115 \mathrm{TOP}+$, Poland) before being ground and mixed with the oils to obtain samples with $10 \%$ and $30 \%$ by weight of the oil. Samples of $50 \mathrm{~g}$ were packed and sealed using a vacuum packing machine (TEPRO SA Model PP3, Poland) and stored at a room temperature for 56 days. The samples were subjected to storage tests, including determination of total polyphenols by the Follin-Ciocalteu method [21], 2,2-diphenyl-1picrylhydrazyl (DPPH) radical binding power [22], antioxidant activity by the $\mathrm{ABTS}^{\bullet+}$ method [23], the ferric reducing antioxidant power of the extracts (FRAP) [24], and determination of acid value (AV) and peroxide value (PV). The analyses were performed on Day 0 and after Day 7, 14, 28 , and 56 of storage.

2.2. Content of Fatty Acids. The fatty acid profile of the test samples was analyzed by gas chromatography coupled with mass spectrometry, whereby the compositions of the obtained methyl esters were determined.

2.3. Preparation of Fatty Acid Methyl Esters (FAME). The tests were carried out using the methodology developed by Maślak et al. [25]. About $50 \mathrm{mg}$ of the fat test sample was hydrolyzed with $7 \%$ methanolic solution of potassium hydroxide $(2 \mathrm{~mL})$ for 5 minutes at the boiling point of the solvent. The resulting fatty acid salts were esterified by addition of $3 \mathrm{~mL} 14 \%$ methanolic solution of boron trifluoride and kept at its boiling point for 5 minutes. On completion of the reaction, $15 \mathrm{~mL}$ cyclohexane was added, and the organic fraction was washed with sodium hydrocarbonate $(2 \times 10 \mathrm{~mL})$ and brine, obtaining a neutral $\mathrm{pH}$. The organic solution was dried over anhydrous sodium sulfate. After concentrating the solvent, the resulting esters were kept at $-20^{\circ} \mathrm{C}$ until GC.

2.4. Chromatographic Analyses. The fatty acid profiles of the test samples were analyzed using gas chromatography coupled with mass spectrometry (Saturn Chrompack 2000/2000). Separation was effected using a nonpolar column ZB WAXMS $(30 \mathrm{~m} \times 0.25 \mathrm{~mm} \times 0.25 \mu \mathrm{m}$ film from Zebron, Phenomenex). The measurements were carried out by ionization using electrons (so-called "electron impact", EI) at the following conditions: ionization $70 \mathrm{eV}$, rate 1 scan per second, and split ratio $1: 40$. The temperature program was as follows: heating rate $5^{\circ} \mathrm{C} / \mathrm{min}$ from $80^{\circ} \mathrm{C}$ to $200^{\circ} \mathrm{C}$, then $25^{\circ} \mathrm{C} / \mathrm{min}$ to $260^{\circ} \mathrm{C}$, injector temperature $220^{\circ} \mathrm{C}$, and helium gas carrier at $1 \mathrm{~mL}$ per minute. The analyses were carried out with ion collection in the range $(\mathrm{m} / z)$ from 39 to 300 with EI ionization of $70 \mathrm{eV}, 1 \mathrm{scan}$ per second.

The acids in the test samples were identified based on three different analytical methods: (1) comparison of Kovac retention indices, as found by the logarithmic method with respect to linear $n$-alkanes, with reference values from the NIST14 and Adams databases; (2) mass spectra comparison between the unknown compound and the spectrum in the NIST14 database; and (3) comparison of retention times and mass spectra of available chromatographic standards, Sigma-Aldrich, mix of 37 chromatographic standards.

2.5. Analysis of Phenolic Content and Antioxidant Activity. The phenolic content and antioxidant activity of the formulations were determined using the UV-2401PC spectrophotometer from Shimadzu.

The extract for analyses was prepared by weighing $0.5 \mathrm{~g}$ of the formulation and adding enough $50 \%$ aqueous solution of methanol ( $50 \%$ aqueous solution of methanol $\left.+\mathrm{SO}_{2}(1 \mathrm{ml} / \mathrm{l})\right)$ to obtain a volume of $5 \mathrm{ml}$, keeping on water bath for $15 \mathrm{~min}$, and cooling for 12 hours. The resulting solution was filtered. The following parameters were determined for the extracts.

2.5.1. Total Phenolic Compound Content Analysis. Total phenolic content by the Follin-Ciocalteu method in which phenol compounds, among other ones, form a colored complex with the Follin-Ciocalteu reagent (a mixture of sodium tungstate, sodium molybdate, and lithium sulfate in a medium composed of phosphoric and hydrochloric acids); the complex is green-blue. After oxidation, the complex was analyzed spectrophotometrically at wavelengths starting at $765 \mathrm{~nm}$. The phenolic content was calculated as gallic acid (GA). 
2.5.2. Free-Radical Scavenging Ability by the Use of a DPPH Radical. 2,2-Diphenyl-1-picrylhydrazyl (DPPH) radical binding power, which consists in reacting the antioxidants present in the test sample, reduce the stable nitrogen radical 2,2-diphenyl-1-picrylhydrazyl (DPPH), thereby decreasing absorbance measured at $517 \mathrm{~nm}$. The active radical solution is purple, and its discoloration indicates that the previously unpaired electron has been paired. The intensity of discoloration of the DPPH solution after addition of the solution containing the antioxidants is a measure of their free-radical scavenging ability.

\subsubsection{Thiobarbituric Acid Reactive Substances (TBARS)} Assay. Antioxidant activity by the method with $\mathrm{ABTS}^{\bullet+}$ enables the quantitative assessment of free-radical scavenging ability of a given component to quench the stable ABTS ${ }^{\circ+}$ radical (2,2'-azine-bis acid (3-ethylenebenzothiazoline $\mathrm{ABTS}^{\bullet+}$ ). Absorbance was measured at wavelength $\lambda=734 \mathrm{~nm}$.

2.5.4. Ferric Reducing Antioxidant Power (FRAP) Assay. The FRAP is based on the reduction of ferric 2,4,6-tris(2pyridyl)-1,3,5-triazine [Fe(III)-TPTZ] to the ferrous complex at low $\mathrm{pH}$, followed by spectrophotometric analysis. Quantitative analyses were performed by the external standard method using ferrous sulfate as the reference standard and correlating the absorbance $(\lambda 593 \mathrm{~nm})$ with the concentration.

The results of antioxidant capability of DPPH, $\mathrm{ABTS}^{\bullet+}$, and FRAP were expressed in $\mu \mathrm{mol}$ Trolox/g of sample. Determination of the peroxide value (PV) as an indicator of the original products of oxidation was performed according to the procedure described in PN-ISO 3960-2016 [26], whereas the acid value (AV) was found by the method described in PN-ISO 660-2010 [27]. Determinations of PV and $\mathrm{AV}$ were carried out for pure linseed and fish oils and for the formulations prepared by mixing the oil with the apple pomace, in triplicate for every sample.

The data of apple pomace and linseed oil included in Tables 1-4 and Figures 1 and 2 are from the $\mathrm{PhD}$ dissertation of Kinga Śpitalniak-Bajerska.

2.6. Statistical Analysis. A statistical analysis of the numerical values, obtained in the tests, was performed using the Statistica 10.0 software (StatSoft, Tulsa, OK, USA), a twoway analysis of variance (ANOVA). The significance of differences between the means was assessed using the Duncan test. Determined arithmetic means $(\bar{x})$, standard deviations (SD), and standard error of mean (SEM) were also determined.

\section{Results and Discussion}

Total phenolic content and the antioxidant activity (DPPH, FRAP, and $\mathrm{ABTS}^{\circ+}$ ) in the "Cortland" apple pomace before addition of the fats are shown in Table 5. Total polyphenols changed immediately after seven days. Their level was mainly shaped by storage times $(p<0.01)$, whereas the effect of the linseed or fish oil content was insignificant. The lowest reduction of total polyphenols was found in pure pomace. The addition of $10 \%$ of the fish or linseed oil exerted a lesser effect on changes in the phenolic content during storage than a higher oil dosage (30\%) (Table 1). However, the decrease in polyphenols was smaller for the test samples containing the apple pomace with the linseed oil. The most observable decrease in that value was detected, on Day 7 of the tests, for samples with $30 \%$ of linseed or fish oil. In apple peels alone, total phenolic content may range from 150 to $700 \mathrm{mg}$ $\mathrm{GA} / 100 \mathrm{~g}$ [2] or be as high as $830.9 \mathrm{mg} \mathrm{GA} / 100 \mathrm{~g}$ [28]. Earlier studies by the present authors indicate that the phenolic content of apple pomace was higher- $1385.44 \mathrm{mg} \mathrm{GA} / 100 \mathrm{~g}$ [20]. Differences in the concentrations of active compounds in the apple pomace tested are attributable to many factors, including the fruit variety, cultivation, and weather conditions, as well as the juice production process conditions.

Antioxidant activity of the alcoholic extracts of apple pomace is shown in Tables 2-4. The findings are presented in the same units, as TEAC (Trolox equivalent antioxidant capacity). Differences in the antioxidant activity among the three methods are attributed to differences in the responses of iron and the radicals to the amount and quality of the compounds present in the apple pomace. On Day 7, the highest DPPH radical quenching ability was detected for the apple pomace enriched with $10 \%$ of linseed oil (Table 2). No changes in their activity with respect to DPPH radical were observed for extracts with $10 \%$ of fish oil (15.2 vs. $14.55 \mu \mathrm{mol}$ Trolox/g sample). Lower activity with respect to DPPH radical was observed at the end of the experiment in the samples containing $30 \%$ of linseed oil, which also showed a stronger drop in antioxidant activity. The study revealed a greater decrease in activity towards DPPH after 56 days for pure pomace and apples mixed with the linseed oil than with the fish oil, regardless of the fat content. The linseed oil contains natural antioxidants such as tocopherols, tocotrienols, carotenoids, phenolic compounds, and sterols $[29,30]$. The fact that the test samples with the linseed oil showed lower antioxidant activity could be explained by the antagonistic effect of the antioxidants in the oil and in the apple pomace, which could also intensify the oil oxidation process.

After seven days, the highest $\mathrm{Fe}^{3+}$ reducing power was observed for the samples of apple pomace mixed with $10 \%$ linseed oil (Table 3). The storage tests confirmed a significant $(p<0.01)$ effect of oil dose on the value of FRAP. Higher contents of the fish oil and linseed oil resulted in lower values of FRAP. On Day 56, the highest $\mathrm{Fe}^{3+}$ reducing power was observed for the apple pomace with $10 \%$ of the fish oil. There was a decrease in the value of FRAP over time; however, the changes were not significant. On Day 28, the value of FRAP dropped in all the groups by a comparable fraction. On Day 7, the ABTS tests showed similar values for the apple pomace samples with $10 \%$ and $30 \%$ of the linseed oil (29.06 and $29.65 \mu \mathrm{mol}$ Trolox $/ \mathrm{g}$, respectively). On the final day, the antioxidant activity towards $\mathrm{ABTS}^{\bullet+}$ radicals was higher for the apple pomace enriched with the fish oil (especially for the $10 \%$ samples), as compared with those mixed with the linseed oil (Table 4).

In this paper, dried apple pomace was used as the natural source of antioxidants. Many authors who have tested apples 
TABLE 1: The content of total polyphenols in the test formulations during storage (mg GA/100 g).

\begin{tabular}{|c|c|c|c|c|c|c|c|}
\hline \multirow{2}{*}{ Total phenolic mg GA/100 g (ml) } & \multicolumn{5}{|c|}{ Storage time (day) } & \multirow{2}{*}{ SEM } & \multirow{2}{*}{$p$ value of time } \\
\hline & 0 & 7 & 14 & 28 & 56 & & \\
\hline Pure pomace & $613.74^{\mathrm{Aa}}$ & 585.57 & 555.60 & 538.29 & 530.20 & 16.89 & 0.01 \\
\hline Pomace + fish oil $10 \%$ & $563.96^{\mathrm{Ab}}$ & $423.81^{\mathrm{A}}$ & $411.36^{\mathrm{A}}$ & $369.4^{\mathrm{A}}$ & $279.99^{\mathrm{Ba}}$ & 17.59 & $<0.01$ \\
\hline Pomace + linseed oil $10 \%$ & $571.31^{\mathrm{Ab}}$ & $451^{\mathrm{A}}$ & $375.59^{\mathrm{B}}$ & $298.01^{\mathrm{Ba}}$ & $308.79^{\mathrm{Bb}}$ & 17.46 & $<0.01$ \\
\hline Pomace + fish oil $30 \%$ & $441.36^{\mathrm{B}}$ & $354.93^{\mathrm{Ba}}$ & $279.82^{\mathrm{B}}$ & $290.43^{\mathrm{B}}$ & $197.59^{\mathrm{A}}$ & 14.79 & 0.01 \\
\hline Pomace + linseed oil $30 \%$ & $454.36^{\mathrm{B}}$ & $389.75^{\mathrm{Bb}}$ & $319.9^{\mathrm{C}}$ & $279.3^{\mathrm{Bb}}$ & $218.97^{\mathrm{A}}$ & 17.20 & $<0.01$ \\
\hline
\end{tabular}

The letters A, B, and C in the same columns indicate statistically high significant differences $(p<0.01)$. The letters a and b in the same columns indicate statistically significant differences $(p<0.05)$. SEM, standard error of the mean.

TABLE 2: The antioxidant activity (DPPH) apple pomace together with the tested oils ( $\mu$ mol Trolox/g).

\begin{tabular}{lccccccc}
\hline \multirow{2}{*}{ DPPH $(\mu$ mol Trolox/g sample) } & \multicolumn{3}{c}{ Storage time (day) } & \multicolumn{2}{c}{ SEM } & $p$ value of time \\
\hline Pure pomace & 0 & 7 & 14 & 28 & 56 & 0.39 & $<0.01$ \\
Pomace + fish oil 10\% & 14.13 & 13.20 & 11.10 & 10.50 & 9.30 & 0.42 & 0.93 \\
Pomace + linseed oil 10\% & 15.51 & $15.20^{\mathrm{A}}$ & $15.10^{\mathrm{A}}$ & $14.90^{\mathrm{A}}$ & $14.55^{\mathrm{A}}$ & 0.44 & $<0.01$ \\
Pomace + fish oil 30\% & 15.60 & $15.47^{\mathrm{A}}$ & $15.95^{\mathrm{A}}$ & $14.11^{\mathrm{A}}$ & $11.28^{\mathrm{B}}$ & 0.53 & 0.01 \\
Pomace + linseed oil 30\% & 16.71 & $15.9^{\mathrm{A}}$ & $10.42^{\mathrm{B}}$ & $11.25^{\mathrm{B}}$ & 12.38 & 0.53 & 0.44 \\
\hline
\end{tabular}

The letters A and B in the same columns indicate statistically high significant differences $(p<0.01)$. SEM, standard error of the mean.

TABle 3: The antioxidant activity (FRAP) of apple pomace together with the tested oils ( $\mu$ mol Trolox/g).

\begin{tabular}{|c|c|c|c|c|c|c|c|}
\hline \multirow{2}{*}{ FRAP ( $\mu$ mol Trolox/g sample) } & \multicolumn{5}{|c|}{ Storage time (day) } & \multirow{2}{*}{ SEM } & \multirow{2}{*}{$p$ value of time } \\
\hline & 0 & 7 & 14 & 28 & 56 & & \\
\hline Pure pomace & $12.57^{\mathrm{A}}$ & $11.90^{\mathrm{Aa}}$ & $11.20^{\mathrm{Aa}}$ & $10.50^{\mathrm{A}}$ & $10.40^{\mathrm{A}}$ & 0.68 & 0.07 \\
\hline Pomace + fish oil $10 \%$ & 21.20 & $20.82^{\mathrm{B}}$ & $18.6^{\mathrm{B}}$ & $16.84^{\mathrm{B}}$ & $13^{\mathrm{B}}$ & 0.79 & 0.03 \\
\hline Pomace + linseed oil $10 \%$ & $23.41^{\mathrm{B}}$ & $22.2^{\mathrm{B}}$ & $19.36^{\mathrm{B}}$ & $17.06^{\mathrm{B}}$ & $12.57^{\mathrm{B}}$ & 0.91 & $<0.01$ \\
\hline Pomace + fish oil $30 \%$ & 22.31 & $22.0^{\mathrm{B}}$ & $17.56^{\mathrm{b}}$ & $17.78^{\mathrm{B}}$ & $10.95^{\mathrm{A}}$ & 0.48 & 0.14 \\
\hline Pomace + linseed oil $30 \%$ & $23.48^{\mathrm{B}}$ & $17.1^{\mathrm{Ab}}$ & 15.67 & $16.72^{\mathrm{B}}$ & 11.36 & 0.82 & $<0.01$ \\
\hline
\end{tabular}

The letters A and B in the same columns indicate statistically high significant differences $(p<0.01)$. The letters a and $\mathrm{b}$ in the same columns indicate statistically significant differences $(p<0.05)$. SEM, standard error of the mean.

TABLE 4: The antioxidant activity $\left(\mathrm{ABTS}^{\bullet+}\right)$ of apple pomace together with the tested oils $(\mu \mathrm{mol}$ Trolox/g).

\begin{tabular}{lccccccc}
\hline \multirow{2}{*}{ ABTS ( $\mu$ mol Trolox/g sample) } & \multicolumn{3}{c}{ Storage time (day) } & \multicolumn{2}{c}{ SEM } & $p$ value of time \\
& 0 & 7 & 14 & 28 & 56 & 1.45 & 0.01 \\
Pure pomace & 27.93 & 26.89 & $25.62^{\mathrm{a}}$ & $24.10^{\mathrm{A}}$ & $18.54^{\mathrm{A}}$ & 1,69 & $<0.01$ \\
Pomace + fish oil 10\% & 36.30 & $35.56^{\mathrm{A}}$ & $24.58^{\mathrm{a}}$ & $17.35^{\mathrm{Ba}}$ & $14.18^{\mathrm{b}}$ & 1.41 & $<0.01$ \\
Pomace + linseed oil 10\% & 32.41 & 29.06 & $24.35^{\mathrm{a}}$ & $10.08^{\mathrm{C}}$ & 13.69 & 1.56 & $<0.01$ \\
Pomace + fish oil 30\% & 28.75 & $24.8^{\mathrm{B}}$ & $24.1^{\mathrm{a}}$ & $12.38^{\mathrm{b}}$ & 13.87 & $1.54^{\mathrm{Ba}}$ & 1.50 \\
Pomace + linseed oil 30\% & 34.62 & 29.65 & $19.93^{\mathrm{b}}$ & 14.74 & 11.01 & $<0.01$ \\
\hline
\end{tabular}

The letters A and B in the same columns indicate statistically high significant differences $(p<0.01)$. The letters a and $\mathrm{b}$ in the same columns indicate statistically significant differences $(p<0.05)$.

or apple pomace confirm their high antioxidant activity, although its specific value largely depends on the fruit variety $[2,31,32]$. Reduced content of polyphenols that we observed on Day $14(p<0.01)$ manifested itself also in lower antioxidant activity, both for the apple pomace and for the samples with the linseed oil. Any later changes in the polyphenolic content were less severe. High phenolic content in apples has a significant effect on their antioxidant activity [32]. Apple peel extract was proved to have a favorable effect on the inhibition of lipid peroxidation [2].
Synthetic antioxidants, with a potentially undesirable effect on human and animal health, are commonly used in the food-processing industry and animal feed production [2].

The metal ion reducing power is one of the mechanisms of action of antioxidants and is typical of secondary antioxidants [33]. A large number of antioxidants have reducing properties. In the FRAP method, $\mathrm{Fe}^{3+}$ ions are the indicator: they are reduced to $\mathrm{Fe}^{2+}$ forming a colored complex with 2,4,6-tripyridyl-S-triazine (TPTZ). An increase in the absorbance of that complex indicates a high level of 


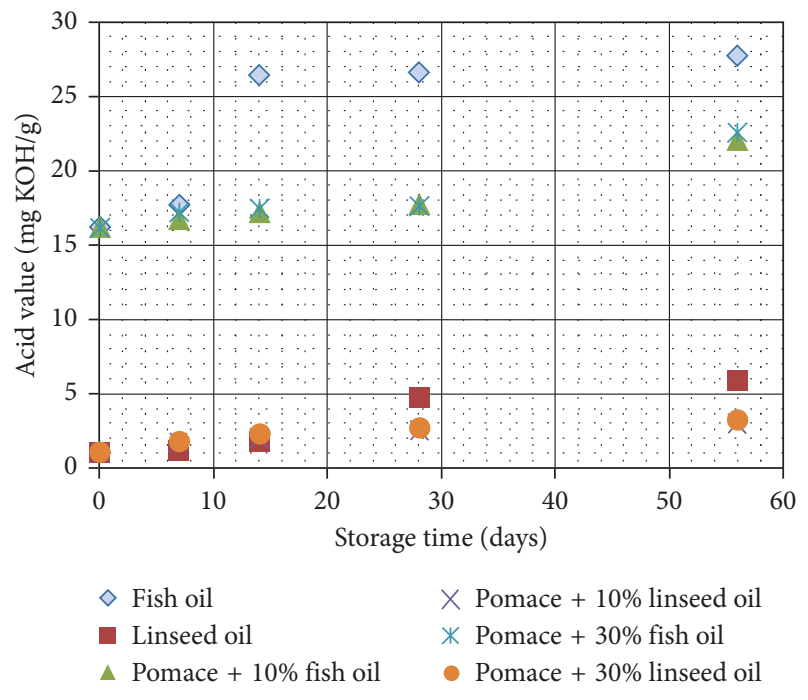

Figure 1: Changes in acid number (mg KOH/g) of the test oils stored with the addition of apple pomace.

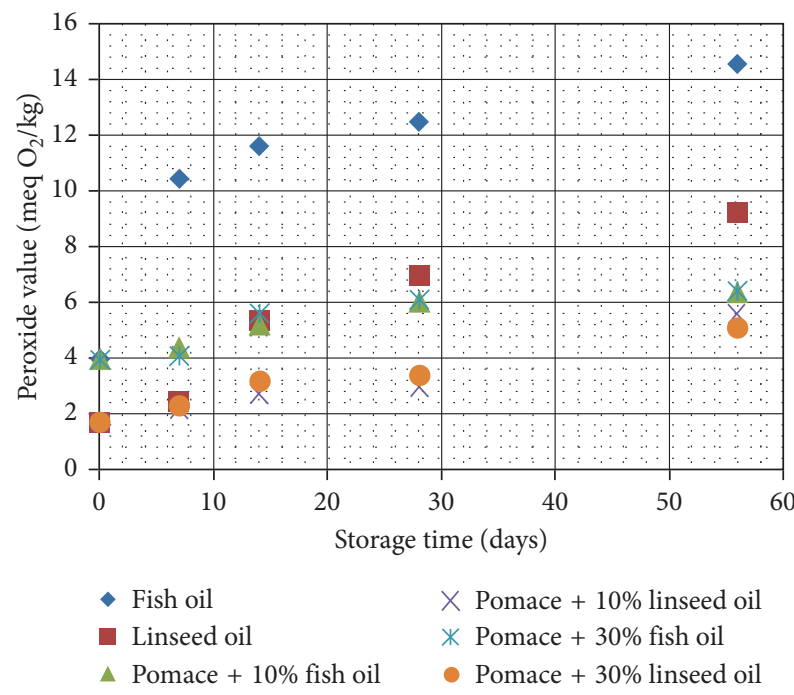

Figure 2: Changes in peroxide value $\left(\mathrm{meq} \mathrm{O}_{2} / \mathrm{kg}\right.$ ) of the test oils stored with the addition of apple pomace.

TABLE 5: The content of total polyphenols and antioxidant activity (DPPH, FRAP, and $\left.\mathrm{ABTS}^{+}\right)$of apple pomace ( $\mu \mathrm{mol}$ Trolox/g).

\begin{tabular}{lc}
\hline Item & Initial sample $(\bar{x} \pm$ SD $)$ \\
\hline Total polyphenols & $613.74 \pm 19.19$ \\
DPPH & $14.13 \pm 0.89$ \\
FRAP & $12.57 \pm 2.56$ \\
ABTS & $27.93 \pm 6.83$ \\
\hline
\end{tabular}

antioxidants in the investigated material. On the final day of the experiment, the samples containing apple pomace with $30 \%$ of the fish oil showed the lowest $\mathrm{Fe}^{3+}$ ion ferric reducing power $(10.95 \mu \mathrm{mol}$ Trolox/g sample), whereas the highest value was observed in the samples with $10 \%$ of the fish oil (10.95 $\mu \mathrm{mol}$ Trolox/g sample) (Table 3). In similar studies, ethanolic extracts of frozen apple peels more strongly inhibited the oxidation of fish oil than synthetic antioxidants such as BHT (butylhydroxytoluene) [28]. Also a green-tea extract appeared to be more powerful than BHA (butylhydroxyanisol) in inhibiting the oxidation of fish oil [34].

Sea fish and sea animals in general, as well as the oils derived from them, are a rich source of EPA and DHA acids $[35,36]$. Among oil plants, $\alpha$-linolenic acid is abundant in linseed oil [37] as well as in Camelina sativa [38]. For analyses of the fatty acid profiles for fats using more complex matrices (dried apple pomace), the most recommendable solution is to use a gas chromatography apparatus coupled with a mass spectrometer (GC-MS). For the reasons stated above, the solution was applied in the present study.

The fish oil tested herein was characterized by a higher content of C16:0, C16:1, and C18:1 n-9, lower content of C18:0, C18:2 n-6, C18:3n-3, and total number of polyunstaturated fatty acids (PUFA) $n-3$, as compared with the linseed oil. The content of $\alpha$-linolenic acid (ALA) was high in the linseed oil, compared with the fish oil. The storage of the fish oil mixed with the apple pomace for 56 days had no effect on its content of C18:3n-3, whereas a decrease in the amount of that fatty acid was detected in the linseed oil samples mixed with the apple pomace (Table 6). The specific apple pomace used and the fact that the fish oil was stored in a sealed container were not found to have an effect on the level of EPA although that of DHA was reduced (4.98 vs. $5.12 \%$ at the beginning of the experiment). The addition of apple pomace more effectively limited the growth of the saturated acid content in the fish oil, in comparison with the linseed oil, on the final day of testing. Generally, after 56 days of storage, PUFAs increased in fish oil, whereas in linseed oil, it decreased.

The formulation tested in our study is applicable in animal feed production for modification of the fatty acid profile in animal tissues and milk. Supplementation of cow feeds with fish oil or a lipid complex based on fish oil and vegetable oils caused a considerable increase in the content of CLA in milk fat $[36,39]$. Increasing the content of dietary FA (CLA, and $n-3 \mathrm{FA}$ ) and maintaining a favorable ratio between $n-3$ and $n-6$ FA in milk will enhance the nutritive and therapeutic value of dairy products [40].

On the starting day of the experiment, AV was $16.17 \mathrm{mg} \mathrm{KOH} / \mathrm{g}$ and $1.05 \mathrm{mg} \mathrm{KOH} / \mathrm{g}$ in the fish oil and linseed oil, respectively (Figure 1). After 56 days of storage, $\mathrm{AV}$ increased to $27.69 \mathrm{mg} \mathrm{KOH} / \mathrm{g}$ and $4.08 \mathrm{mg} \mathrm{KOH} / \mathrm{g}$ for the fish and linseed oil, respectively $(p<0.01)$. The addition of apple pomace limited the increase as early as after 7 days of storage for the fish oil and after 14 days for the linseed oil, and it slowed down any further increase in AV. The slowest increase in AV during the experiment was observed for the samples with $10 \%$ of the linseed oil. For the linseed oil, the acid value did not exceed the coldpressed oil values, as recommended in the Codex Alimentarius [41] ( $\mathrm{AV} \leq 4 \mathrm{mg} \mathrm{KOH} / \mathrm{g})$. By contrast with refined oils, the acid value for cold-pressed oils may increase due to the progressing hydrolysis (enzymes and trace amount of water in the oil and air moisture) [1]. For the fish oil, the value should be a maximum of $3 \mathrm{mg} \mathrm{KOH} / \mathrm{g}$, whereas for oils rich in phospholipids, the permissible 
TABLE 6: Fatty acid content (\%) in fish and linseed oil or in formulations (oil + apple pomace) before and after 56 days of storage under anaerobic conditions.

\begin{tabular}{|c|c|c|c|c|c|c|}
\hline \multirow[b]{2}{*}{ Fatty acid } & \multicolumn{6}{|c|}{ Oils and preparations during the storage period } \\
\hline & Fish oil & Fish oil after $56 \mathrm{~d}$ & $\begin{array}{c}\text { Fish oil + apple pomace } \\
\text { after } 56 \mathrm{~d}\end{array}$ & Linseed oil & Linseed oil after $56 \mathrm{~d}$ & $\begin{array}{l}\text { Linseed oil }+ \text { apple } \\
\text { pomace after } 56 \mathrm{~d}\end{array}$ \\
\hline C14:0 & 2.78 & 2.72 & 2.36 & 0.02 & 0.02 & 0.33 \\
\hline $\mathrm{C} 15: 0$ & 0.27 & 0.23 & 0.34 & nd & nd & nd \\
\hline $\mathrm{C} 16: 0$ & 12.85 & 11 & 11.94 & 5.29 & 5.39 & 6.15 \\
\hline $\mathrm{C} 16: 1$ cis & 4.40 & 4.39 & 4.65 & 0.03 & 0.02 & 0.34 \\
\hline C17:0 & 1.96 & 0.96 & 1.15 & 0.02 & 0.03 & 0.20 \\
\hline $\mathrm{C} 17: 1 \mathrm{cis}$ & 0.21 & 0.23 & 0.24 & nd & nd & nd \\
\hline $\mathrm{C} 18: 0$ & 2.97 & 2.92 & 3.05 & 3.97 & 4.37 & 4.58 \\
\hline $\mathrm{C} 18: 1 \mathrm{n}-9$ cis & 33.12 & 33.41 & 33.01 & 20.75 & 21.07 & 21.12 \\
\hline C18:1 n-9 trans & 3.37 & 3.49 & 3.41 & 0.80 & 0.86 & 1.12 \\
\hline C18:2 n-6 & 10.90 & 11.29 & 11.6 & 15.81 & 16.49 & 17.07 \\
\hline C18:3 n-6 & 0.32 & 0.42 & 0.38 & 0.03 & 0.01 & 0.63 \\
\hline C18:3 n-3 & 4.12 & 382 & 3.97 & 52.73 & 51.01 & 47.35 \\
\hline $\mathrm{C} 18: 4 n-3$ & 1.04 & 1.14 & 1.06 & nd & nd & nd \\
\hline C20:0 & 0.24 & 0.30 & 0.27 & 0.12 & 0.19 & 0.16 \\
\hline C20:1 n-9 & 5.03 & 5.39 & 5.26 & 0.15 & 0.18 & 0.26 \\
\hline C20:2 n-6 & 0.75 & 0.84 & 0.74 & 0.13 & 0.18 & 0.26 \\
\hline C20:3 n-6 & 0.37 & 0.46 & 0.37 & nd & nd & nd \\
\hline C20:3 n-3 & 0.65 & 1.45 & 1.7 & nd & nd & nd \\
\hline $\mathrm{C} 20: 4 n-6$ & 0.53 & 0.58 & 0.31 & 0.06 & 0.09 & 0.34 \\
\hline C20:5 n-3 & 3.03 & 3.11 & 3.15 & nd & nd & nd \\
\hline $\mathrm{C} 21: 0$ & 0.14 & 0.18 & 0.14 & nd & nd & nd \\
\hline C22:0 & 4.50 & 4.97 & 4.65 & nd & nd & nd \\
\hline C22:1 n-9 & 0.40 & 0.11 & 0.12 & nd & nd & nd \\
\hline $\mathrm{C} 22: 5 n-6$ & 0.93 & 1.06 & 1.15 & nd & nd & nd \\
\hline $\mathrm{C} 22: 6 n-3$ & 5.12 & 5.53 & 4.98 & nd & nd & nd \\
\hline Saturated FA & 25.71 & 23.28 & 23.90 & 9.42 & 10.00 & 11.42 \\
\hline Unsaturated FA & 74.29 & 76.72 & 76.10 & 90.49 & 89.91 & 88.49 \\
\hline Monounsaturated FA & 46.53 & 47.02 & 46.69 & 21.73 & 22.13 & 22.84 \\
\hline Polyunsaturated FA & 27.76 & 29.70 & 29.41 & 68.76 & 67.78 & 65.65 \\
\hline Total $n-6$ FA & 13.80 & 14.65 & 14.55 & 16.03 & 16.77 & 18.30 \\
\hline Total $n-3$ FA & 13.96 & 15.05 & 14.86 & 52.73 & 51.01 & 47.35 \\
\hline
\end{tabular}

nd $=<0.01$ or not detected.

value of $\mathrm{AV}$ is $30 \mathrm{mg} \mathrm{KOH} / \mathrm{g}$. The high acid value of the fish oil may have been caused by long storage period or a high content of free fatty acids. According to Rotkiewicz and Konopka [42], oils tend to be hydrolyzed at a rate which increases with the content of free fatty acids they have just after being pressed.

The fat oxidation process intensity, as measured with their PV, indicates the current amount of peroxides. Before using the apple pomace, the $\mathrm{PV}$ was $1.7 \mathrm{meq} \mathrm{O}_{2}$ per $1 \mathrm{~kg}$ of the linseed oil and $3.99 \mathrm{meq} \mathrm{O}_{2}$ per $1 \mathrm{~kg}$ of the fish oil (Figure 2). The permissible value for vegetable oils is $<15$ meq $\mathrm{O}_{2} / \mathrm{kg}$ [41]. Long-term storage of linseed oil and apple pomace caused a lower increase in PV, in comparison with pure oil samples. The increase in the peroxide value for the linseed oil could be due to the fact that we used coldpressed linseed oil, that is, a nonrefined oil containing accompanying compounds [43], such as primary and secondary products of oxidation, free fatty acids, colorants, metals, or incomplete triacylglycerols that could have intensified the oxidation process. The steepest increase in the peroxide curve was detected for the pure fish oil $(p<0.01)$. On the final day of the experiment, PV of the fish oil (10 and $30 \%)$ mixed with apple pomace was 6.35 and 6.43 meq $\mathrm{O}_{2}$ per $1 \mathrm{~kg}$, respectively, and $14.56 \mathrm{meq}_{2}$ per $1 \mathrm{~kg}$ for the pure fish oil. The fish oil is highly susceptible to oxidation, which is attributed to its high number of 1,4-pentadiene systems in its structure, and the absence of endogenous antioxidants [44]. The linseed oil (which contains $\alpha$-linolenic acid; three double bonds) is less susceptible to oxidation processes, in comparison with, for instance, EPA acid (five bonds) and DHA (six bonds), which are abundant in the fish oil [45]. The oxidation of $\alpha$-linolenic acid may lead to the formation of seven trans isomers, whereas the oxidation of EPA with five bonds produces 32 isomers.

Anaerobic storage of the fish or linseed oils mixed with the apple pomace inhibited the increase of AV and PV in the stored samples. Aerobic conditions tended to result in higher increases in AV and PV, according to earlier reports [20]. 


\section{Conclusions}

The apple pomace was the source of phenolic compounds enhancement of oils stability, evidenced by peroxide and hydroxide value at the end of the study. After 56 days of storage, the total polyphenol contents in all tested combinations of fish or linseed oils with pomace were reduced (46 to 55\%). However, apple pomace used in connection with oils, storage under anaerobic conditions did not significantly increased oxidation or degradation of fatty acids. The highest antioxidant capacity against $\mathrm{DPPH}^{\circ}$ radicals and ABTS radicals cation was found in combination of apple pomace with $10 \%$ of linseed oil content, and the lowest capacity was found in samples with $30 \%$ of linseed oil content. In animals, feeding could be solved in the proposed approach, which makes the product acceptable for livestock breeding. Pomace, as a relative rich source of polyphenols, could improve metabolic and oxidative processes in animals. Therefore, the further research in this direction is necessary.

\section{Data Availability}

The data used to support the findings of this study are available from the corresponding author upon request.

\section{Conflicts of Interest}

The authors declare that there are no conflicts of interest regarding the publication of this paper.

\section{Acknowledgments}

This project was supported by Wroclaw Centre of Biotechnology through the programme "The Leading National Research Centre" (KNOW) for years 2014-2018.

\section{References}

[1] E. Choe and D. B. Min, "Mechanisms and factors for edible oil oxidation," Comprehensive Reviews in Food Science and Food Safety, vol. 5, no. 4, pp. 169-186, 2006.

[2] G. M. Huber and H. P. V. Rupasinghe, "Phenolic profiles and antioxidant properties of apple skin extracts," Journal of Food Science, vol. 74, no. 9, pp. 693-700, 2009.

[3] E. N. Frankel, Lipid Oxidation, Elsevier, New York, NY, USA, 2014.

[4] P. Montero, B. Giménez, M. Pérez-Mateos, and M. C. GómezGuillén, "Oxidation stability of muscle with quercetin and rosemary during thermal and high-pressure gelation," Food Chemistry, vol. 93, no. 1, pp. 17-23, 2005.

[5] D. Bera, D. Lahiri, and A. Nag, "Studies on a natural antioxidant for stabilization of edible oil and comparison with synthetic antioxidants," Journal of Food Engineering, vol. 74, no. 4, pp. 542-545, 2006.

[6] K. A. Omar, L. Shan, Y. L. Wang, and X. Wang, "Stabilizing flaxseed oil with individual antioxidants and their mixtures," European Journal of Lipid Science and Technology, vol. 112, no. 9, pp. 1003-1011, 2010.

[7] Z. U. Rehman, F. Habib, and W. H. Shah, "Utilization of potato peel extract as a natural antioxidant in soybean oil," Food Chemistry, vol. 85, no. 2, pp. 215-220, 2004.
[8] J. E. N. Dolatabadi and S. Kashanian, "A review on DNA interaction with synthetic phenolic food additives," Food Research International, vol. 43, no. 5, pp. 1223-1230, 2010.

[9] U. Samotyja and M. Małecka, "Effects of blackcurrant seeds and rosemary extracts on oxidative stability of bulk and emulsified lipid substrates," Food Chemistry, vol. 104, no. 1, pp. 317-323, 2007.

[10] D. Klensporf-Pawlik and H. Jeleń, "Influence of the addition of raspberry seed extract on changes in the volatile pattern of stored model breakfast cereals," Journal of Agricultural and Food Chemistry, vol. 56, no. 9, pp. 3268-3272, 2008.

[11] G. Ćetković, J. Čanadanović-Brunet, S. Djilas, S. Savatović, A. Mandić, and V. Tumbas, "Assessment of polyphenolic content and in vitro antiradical characteristics of apple pomace," Food Chemistry, vol. 109, no. 2, pp. 340-347, 2008.

[12] B. Suárez, A. L. Álvarez, Y. D. García, G. Barrio, A. P. Lobo, and F. Parra, "Phenolic profiles, antioxidant activity and in vitro antiviral properties of pomace," Food Chemistry, vol. 120, no. 1, pp. 339-342, 2010.

[13] K. Younis and S. Ahmad, "Waste utilization of apple pomace as a source of functional ingredient in buffalo meat sausage," Cogent Food \& Agriculture, vol. 1, no. 1, pp. 11193-11197, 2010.

[14] S. A. Mir, S. J. D. Bosco, M. A. Shah, S. Santhalakshmy, and M. M. Mir, "Effect of apple pomace on quality characteristics of brown rice based cracker," Journal of the Saudi Society of Agricultural Sciences, vol. 16, no. 1, pp. 25-32, 2017.

[15] Y. Li, C. Guo, J. Yang, J. Wei, J. Xu, and S. Cheng, "Evaluation of antioxidant properties of pomegranate peel extract in comparison with pomegranate pulp extract," Food Chemistry, vol. 96, no. 2, pp. 254-260, 2006.

[16] J. D. Wood, M. Enser, A. V. Fisher et al., "Fat deposition, fatty acid composition and meat quality: a review," Meat Science, vol. 78, no. 4, pp. 343-358, 2008.

[17] P. Kairenius, A. Ärölä, H. Leskinen et al., "Dietary fish oil supplements depress milk fat yield and alter milk fatty acid composition in lactating cows fed grass silage-based diets," Journal of Dairy Science, vol. 98, no. 8, pp. 5653-5671, 2015.

[18] A. A. AbuGhazaleh, D. O. Felton, and S. A. Ibrahim, "Milk conjugated linoleic acid response to fish oil and sunflower oil supplementation to dairy cows managed under two feeding systems," Journal of Dairy Science, vol. 90, no. 10, pp. 47634769, 2007.

[19] R. Kupczyński, M. Kuczaj, M. Szołtysik, and T. Stefaniak, "Influence of fish oil, palm oil and glycerol on milk fatty acid composition and metabolism in cows during early lactation," Archives Animal Breeding, vol. 55, no. 6, pp. 540-551, 2012.

[20] R. Kupczyński, K. Śpitalniak, A. Z. Kucharska, and A. Szumny, "Use of waste materials from the food industry to increase the stability of selected oil," Przemysl Chemistry, vol. 96, no. 3, pp. 631-635, 2017.

[21] X. Gao, M. Ohlander, N. Jeppsson, L. Bjork, and V. Trajkorski, "Changes in antioxidant effects and their relationship to phytonutrients in fruits of Sea buckthorn (Hippophae rhamnoides L.) during maturation," Journal of Agricultural and Food Chemistry, vol. 48, no. 5, pp. 1485-1490, 2000.

[22] G. C. Yen and H. Y. Chen, "Antioxidant activity of various tea extracts in relation to their antimutagenicity," Journal of Agricultural and Food Chemistry, vol. 43, no. 1, pp. 27-32, 1995.

[23] R. Re, N. Pellegrini, A. Proteggente, A. Pannala, and M. Yang, "Antioxidant activity applying an improved ABTS radical cation decolorization assay," Free Radical Biology and Medicine, vol. 26, no. 9-10, pp. 1231-1237, 1999. 
[24] I. F. F. Benzie and J. J. Strain, "The ferric reducing ability of plasma (FRAP) as a measure of "Antioxidant Power": the FRAP assay," Analytical Biochemistry, vol. 239, no. 1, pp. 70-76, 1996.

[25] E. Maślak, E. Buczek, A. Szumny et al., "Individual CLA isomers, c9t11 and t10c12, prevent excess liver glycogen storage and inhibit lipogenic genes expression induced by high-fructose diet in rats," BioMed Research International, vol. 2015, Article ID 535982, 10 pages, 2015.

[26] PN-EN ISO 3960:2016, Animal and Vegetable Fats and Oils-Determination of Peroxide Value-Iodometric (Visual) Endpoint Determination, Polish Committee for Standardization, Poland, 2016.

[27] PN-EN ISO 660:2010, Animal and Vegetable Fats and Oils-Determination of Acid Value and Acidity, BSI Standards, London, UK, 2010.

[28] S. Sekhon-Loodu, S. N. Warnakulasuriya, H. V. Rupasinghe, and F. Shahidi, "Antioxidant ability of fractionated apple peel phenolics to inhibit fish oil oxidation," Food Chemistry, vol. 140, no. 1-2, pp. 189-196, 2013.

[29] R. Przybylski, Flax Oil and High Linolenic Oils: Bailey's Industrial Oil and Fat Products, John Wiley \& Sons, Hoboken, NJ, USA, 2005.

[30] B. Bozan and F. Temelli, "Chemical composition and oxidative stability of flax, safflower and poppy seed and seed oils," Bioresource Technology, vol. 99, no. 14, pp. 6354-6359, 2008.

[31] K. Wolfe, X. Wu, and R. H. Liu, "Antioxidant activity of apple peels," Journal of Agricultural and Food Chemistry, vol. 51, no. 3, pp. 609-614, 2003.

[32] A. Fabisiak, S. Li, J. Stawczyk, and D. Witrowa-Rajchert, "The influence of method and apples drying temperature on the antioxidant activity of extracts produced from those dried apples," Zywnosc-Nauka, Technologia, Jakosc, vol. 12, no. 2, pp. 318-327, 2005.

[33] E. N. Frankel, Lipid Oxidation, The Oily Press, Bridgewater, UK, 2005.

[34] M. Przybysz, A. Szterk, M. Zawislak, and E. Dluzewska, "Effect of microencapsulation process and addition of antioxidants on stability of fish oil," Zywnosc-Nauka, Technologia, Jakosc, vol. 21, no. 2, 2014.

[35] A. P. Simopoulos, "The importance of the omega-6/omega-3 fatty acid ratio in cardiovascular disease and other chronic diseases," Experimental Biology and Medicine, vol. 233, no. 6, pp. 674-688, 2008.

[36] R. Bodkowski, K. Czyż, R. Kupczyński, B. Patkowska-Sokoła, P. Nowakowski, and A. Wiliczkiewicz, "Lipid complex effect on fatty acid profile and chemical composition of cow milk and cheese," Journal of Dairy Science, vol. 99, no. 1, pp. 57-67, 2016.

[37] J. Whelan and C. Rust, "Innovative dietary sources of n-3 fatty acids," Annual Review of Nutrition, vol. 26, pp. 75-103, 2006.

[38] U. S. Schwab, M. A. Lankinen, V. D. Mello et al., "Camelina sativa oil, but not fatty fish or lean fish, improves serum lipid profile in subjects with impaired glucose metabolism-a randomized controlled trial," Molecular Nutrition \& Food Research, vol. 62, no. 4, 2018.

[39] A. A. AbuGhazaleh, S. Abo El-Nor, and S. A. Ibrahim, "The effect of replacing corn with glycerol on ruminal bacteria in continuous culture fermenters," Journal of Animal Physiology and Animal Nutrition, vol. 95, no. 3, pp. 313-319, 2011.

[40] S. L. Allred, T. R. Dhiman, C. P. Brennand, R. C. Khanal, D. J. McMahon, and N. D. Luchini, "Milk and cheese from cows fed calcium salts of palm and fish oil alone or in combination with soybean products," Journal of Dairy Science, vol. 89, no. 1, pp. 234-248, 2006.

[41] Codex Alimentarius Commission, Joint FAO/WHO Food Standards Programme. Codex Alimentarius: Fats, Oils and Related Products, Vol. 8, Food \& Agriculture Organization, Rome, Italy, 2001.

[42] D. Rotkiewicz and I. Konopka, "Stability of cold pressed oils from the rapeseed of different quality," Rośliny Oleiste, vol. 19, no. 2, pp. 583-591, 1998.

[43] A. Masłowski, D. Andrejko, B. Ślaska-Grzywna et al., "Impact of the storage temperature and time on the selected quality properties of rapeseed, linseed and cameline seed oil," Inżynieria Rolnicza, vol. 17, no. 1, pp. 115-124, 2013.

[44] M. Y. Baik, E. L. Suhendro, W. W. Nawar, D. J. McClements, E. A. Decker, and P. Chinachoti, "Effects of antioxidants and humidity on the oxidative stability of microencapsulated fish oil," Journal of the American Oil Chemists' Society, vol. 81, no. 4, pp. 355-360, 2004.

[45] U. Erasmus, Fats that Heal, Fats that Kill: The Complete Guide to Fats, Oils, Cholesterol, and Human Health, Book Publishing Company, Summertown, TN, USA, 1993. 

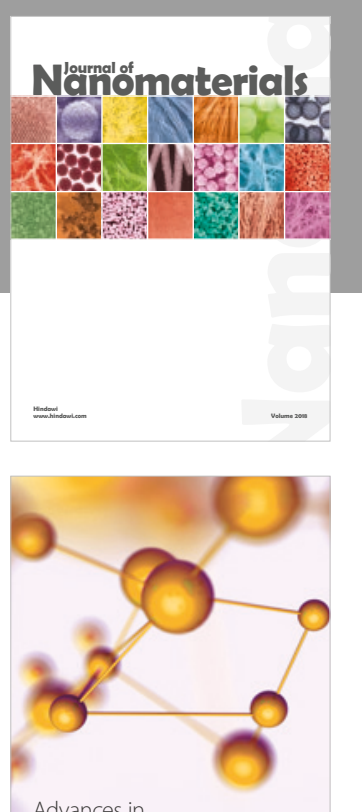

Physical Chemistry
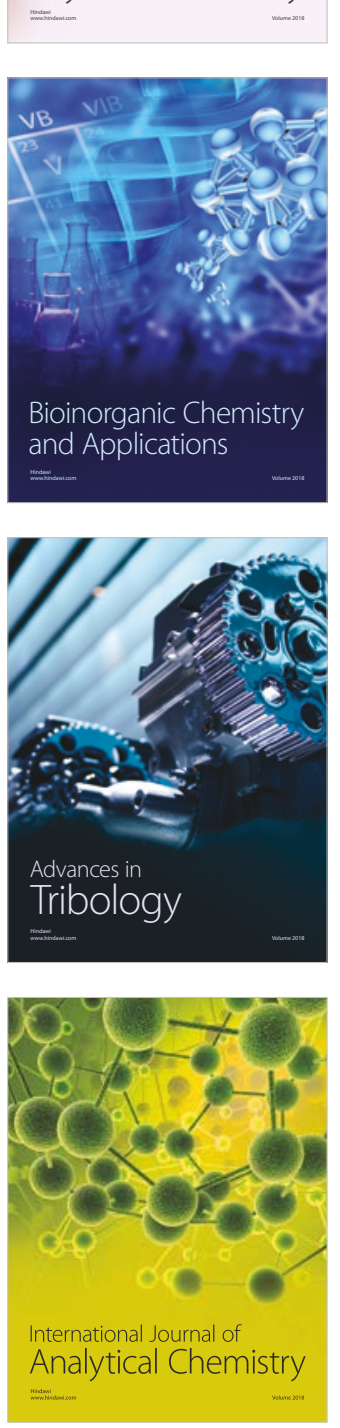

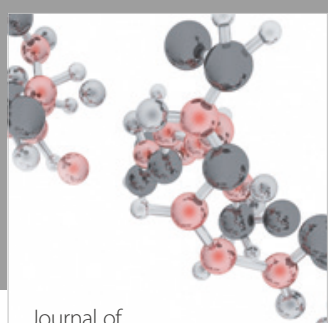

Analytical Methods

in Chemistry

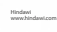

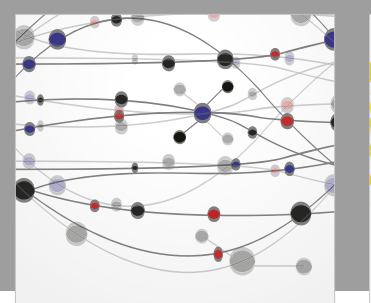

The Scientific World Journal

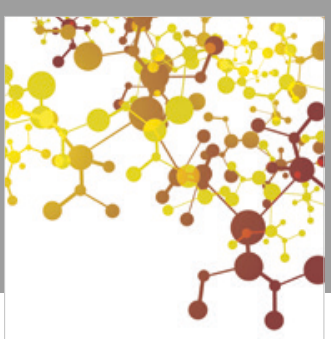

Journal of

Applied Chemistry
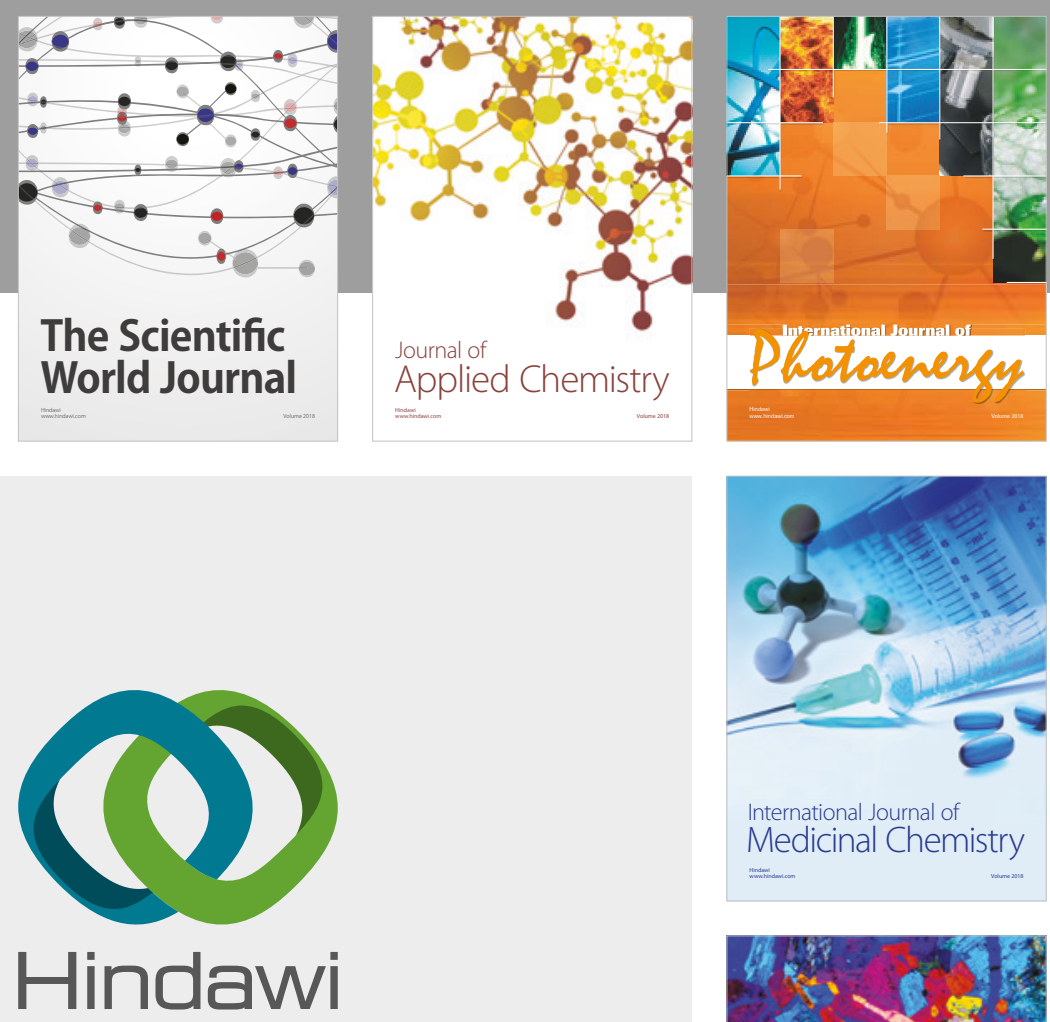

Submit your manuscripts at

www.hindawi.com
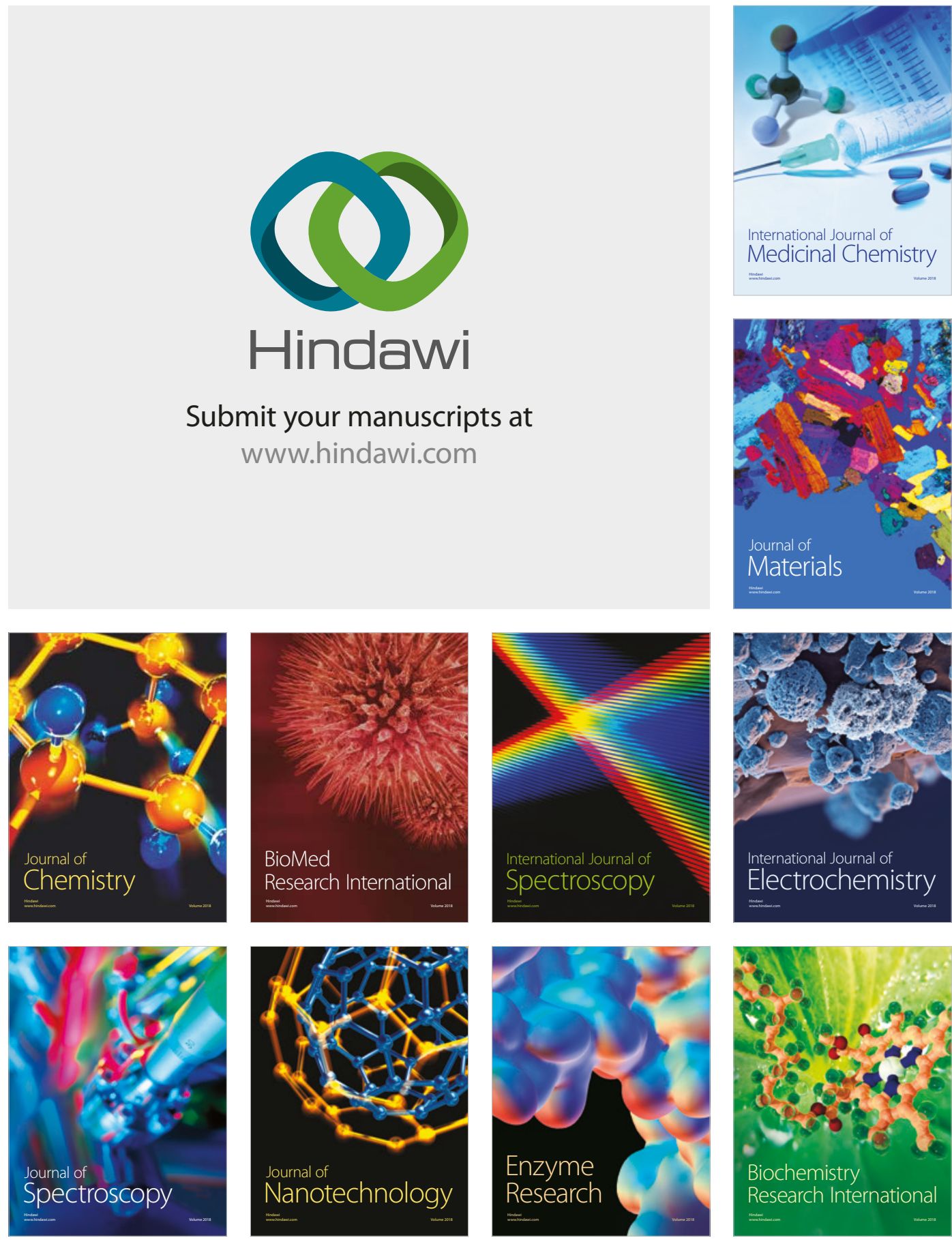
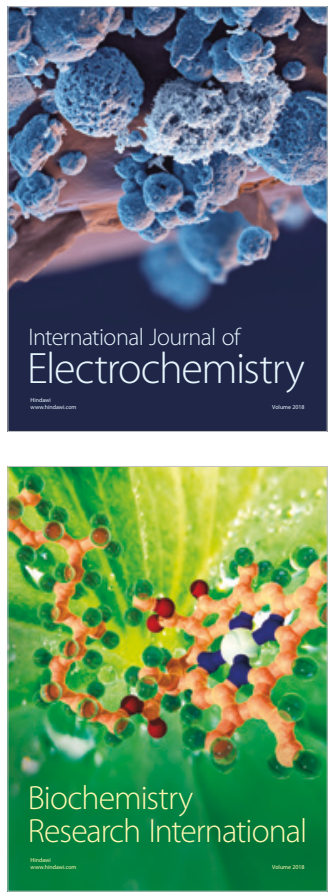